\title{
"Soil Structure Interaction Effect on an Asymmetrical R.C. Building with Shear Walls"
}

\author{
Er. Puneet Sharma, Er. Ankit, Er. Ismit Pal Singh \\ ${ }^{I}$ (Civil Department, ChandigarhUniversity, India) \\ ${ }_{3}^{2}$ (Civil Department, ChandigarhUniversity, India) \\ ${ }_{3}^{3}$ (Civil Department, ChandigarhUniversity, India)
}

\begin{abstract}
Earthquake in populated areas throughout the world causes extensive damage to the various structures that result in catastrophic loss of human life and enormous economic losses. However, the damage can be attributed to the inadequate design of the structures. Sometimes for low to medium rise structures, the analysis and design with respect to lateral forces has generally been a process of checking the vertical load resisting system for its ability to resist lateral forces. However, for tall buildings, the vertical load resisting system cannot resist lateral forces efficiently, it is well recognized that the incorporation of lateral force resisting systems in the form of shear walls, bracing systems etc. improve the structural performance of building subjected to lateral forces due to earthquake excitation.

Further, the position of shear walls in a building alters the response of structure. It is desirable to decide the position of the of the shear walls judicially, so that maximum benefit can be derived. Similarly, adopting realistic approach for structure foundation soil behavior, a flexible approach analysis considering soil structure interaction, also alters the response of structure in terms of bending moment, axial thrust, etc. therefore response of building in terms of forces and bending moment in members, is required to be ascertained, with the placement of shear walls at different possible locations and also with the consideration of soil structure interaction effect. The phenomenon of soil-structure interaction is more pronounced in multi-storied building frames especially, when resting on poor soil, due to possibility of large unequal column loads. Neglecting SSI is reasonable for light structures in relatively stiff soil such as low rise buildings and simple rigid retaining walls. The effect of SSI, however, becomes prominent for heavy structures resting on relatively soft soils for example high-rise buildings, nuclear power plants and elevated-highways on soft soil.
\end{abstract}

Keywords: Seismic, Shear force \& Bending moment, Supports, Soil structure, Elastic hall space.

\section{INTRODUCTION}

A multi-storeyed, multi-panelled frame is a complicated statically indeterminate structure. It consists of a number of beams and columns built monolithically, forming a network. A building frame is subjected to both vertical as well as horizontal loads. The ability of the multi-storeyed building to resist horizontal forces depends upon the rigidity of connections between the beams and columns. If the beams, columns and diaphragm act as a fully rigid system, the structure as a whole is capable of resisting the lateral forces acting on the structure. The high rise structures are subjected to dominant horizontal forces i.e. earthquake forces in addition to gravity forces. Therefore, it is warranted, to make the building earthquake resistant, to resist the effects of ground shaking without collapsing. And hence, shear walls were introduced. Shear walls are vertical elements, made of $\mathrm{RCC}$, of the horizontal force resisting system. Shear walls are constructed to counter the effects of lateral load acting on a structure. In residential construction, shear walls are straight external walls that typically form a box which provides all of the lateral support for the building. When shear walls are designed and constructed properly, they will have the strength and stiffness to resist the horizontal forces. Lateral forces caused by wind, earthquake, and uneven settlement loads, in addition to the weight of structure and occupants; create powerful twisting (torsion) forces. These forces can tear (shear) a building apart. Reinforcing a frame by attaching or placing a rigid wall inside it, maintains the shape of the frame and prevents rotation at the joints. As part of an earthquake resistant building design, these walls are placed in buildings as lift wells, elevators or for storage purposes in plan, reducing lateral displacements under earthquake loads.

Further, In the conventional design, buildings are generally considered to be fixed at their bases. In reality, flexibility of the supporting soil medium allows movement of the foundation resulting in a decrease in global stiffness of the structural system. Therefore the interaction of soil and a structure constructed on the soil layer remains a very critical issue in the application of structural engineering principles during design. The soil structure interaction is the effect of soil, immediately beneath and around the structure on the response of the structure when subjected to external loads, is soil structure interaction. The complexity of soil properties makes it very difficult for structural engineers to create an exact model that emulates the real behaviour of soilstructure interaction problems thereby resulting uncertainty in analysis. When interactive analysis is considered, 
superstructure, foundation and soil are considered as three components of one elastic system. The interaction between the components of elastic system i.e. soil structure system (superstructure, foundation and soil), under loads, depend on interacting elastic effects, on components of system. In the past, during design/analysis processes of engineered structures, it was assumed that the foundation of a structure was fixed to a rigid underlying medium. In the last four decades, however, it has been recognized that SSI alters the response characteristics of a structural system.

In conventional design, SSI is simply ignored in design without establishing whether it will increase or decrease the response of the structure. The position of shear walls in a building alters the response of structure. It is desirable to decide the position of the of the shear walls judicially, so that maximum benefit can be derived. Similarly, adopting realistic approach for structure foundation soil behaviour, a flexible approach analysis considering soil structure interaction, also alters the response of structure in terms of bending moment, axial thrust, settlement etc. therefore response of building in terms of forces and bending moment in members, settlement in foundation is required to be ascertained, due to placement of shear walls at different possible locations and also due to consideration of soil structure interaction.

\section{Need Of The Present Study}

Asymmetrical buildings are subjected to lateral loads, especially seismic loads, eccentricity between centre of mass and centre of rigidity causes horizontal twisting of the structure and it becomes necessary to perform dynamic analysis to ensure that the expected behaviour of the building is simulated in the analytical model. Due to eccentricity, the building may develop significant torsional moments that may eventually lead to high demand on the framing systems, thus justifying the concern for its seismic safety. For tall buildings the vertical load resisting system cannot resist lateral forces efficiently. It has been found that the incorporation of shear walls helps in resisting the lateral forces more efficiently. By constructing shear walls, damages due to effect of lateral forces due to earthquake and high winds can be minimized From economic, structural strength and stiffness considerations, it is essential that the lateral force resisting system be carefully considered in the initial design stage and incorporated as an important feature of design.

On the other hand, Soil -structure-interaction (SSI) effects may be either beneficial or detrimental to the performance of structures. When beneficial, by incorporating SSI effects in the seismic code calculations, more cost-effective designs are possible. For some situations, such as the design or retrofitting of bridges, dams or buried structures, etc., an appropriate inclusion of SSI effects in seismic calculations may bring large design cost savings to our society. There is an urgent need for performing comparative cost-benefit reviews with and without considering rigorously the SSI effects for different types of constructions. When it is determined by calculations that SSI effects can be detrimental to the performance of structures, by mere recognition and taking effective measures, safety and better performance can be achieved.

\subsection{GENERAL}

\section{Methodology}

Elastic half space approach was adopted for the analysis. As the physical representation of elastic half space model is vastly superior to Winkler's model.

Firstly the asymmetrical building frame with different location of shear walls is analysed using conventional approach i.e. fixing the base by providing a fixed support. without considering the effect of SSI. In the next case, the building is analysed with flexible approach i.e. having spring base conditions, that is incorporating the effect of flexibility of soil, the footing is assumed to be resting on elastic medium. In this case six springs, one to accommodate the vertical motion, two to include the translational motion in corresponding horizontal directions and three rotational springs are provided at the foundation level. In the third case ,the building is analysed without shear wall and without SSI. The stiffness of the springs is calculated using the relations given by Richart et.al.(1970). Thirdly the difference between the cases is compared with each other on the bases of axial forces, bending moments, shear force, storey drift and time period. 


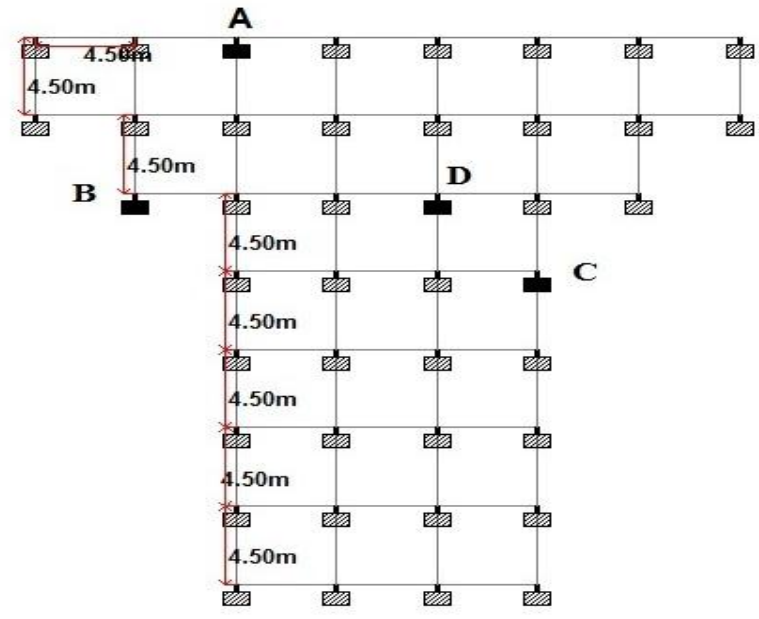

Fig 3.1 Plan of building

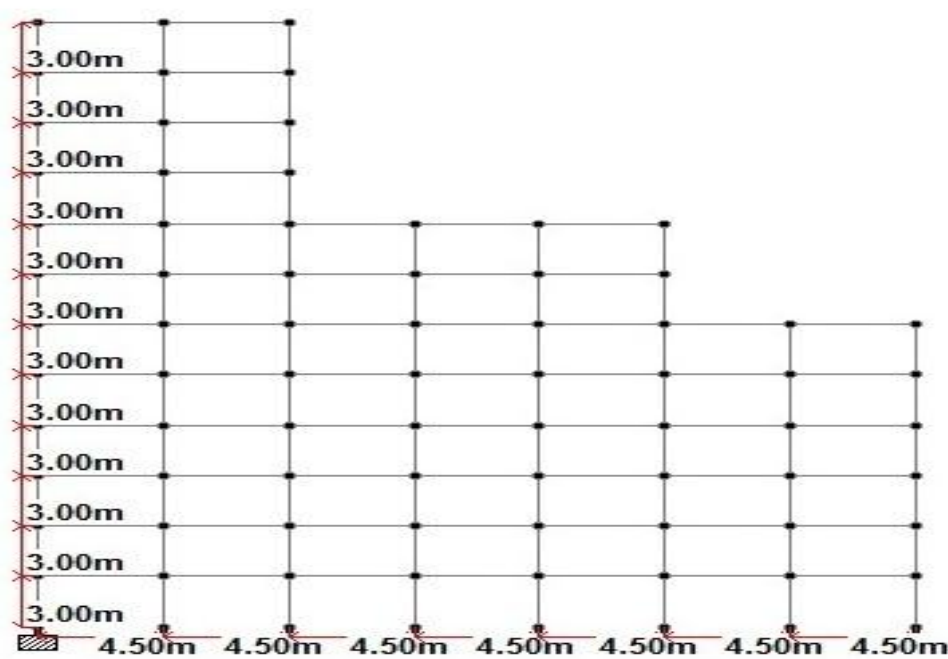

Fig 3.2 Elevation of building

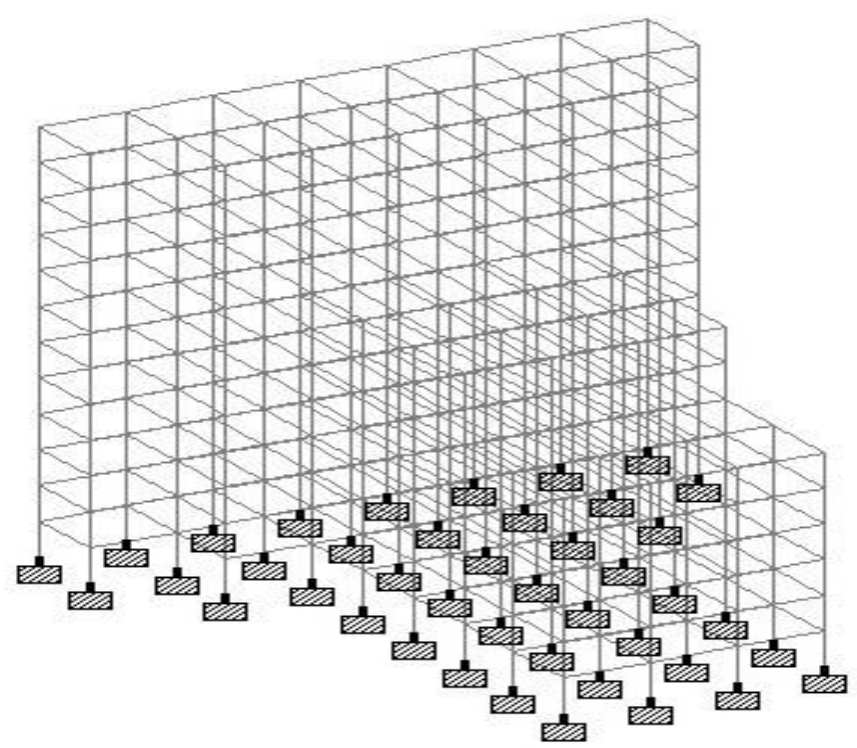

Fig 3.3 Isometric view

The diagram shows the plan of the building, the embraced locations are the members which has been analysed in the present work. 
The present work deals with $3 \mathrm{D}$ multi-bay reinforced concrete building founded on footings resting on loose soil. The connection between columns and footings can be either fixed or fixed but spring. However, it is assumed that the soil offers flexibility to the vertical displacement, horizontal displacement and rotation at the nodded points at the common interface between the footings and soil.

The structural analysis has been carried out using STAAD PRO software which is based on stiffness matrix method. In this work, a multi-bay reinforced building was analysed for different types of loads and load combinations i.e. Gravity Load which include dead load and appropriate percentage of live load (GL); Seismic or Earthquake load (EL). Then the frames were analysed for critical load or load combination.

\subsection{POSITION OF SHEAR WALL'S CONSIDERD IN THE ANALYSIS}

For the present study, two locations of shear walls have been incorporated in the design process.

1. Firstly, shear walls are provided in the external frame of the building, that is in the extreme end location, the shear walls are provided in L shape, in the exterior frame of the building, and a lift well shear wall is provided in the middle frame of the building As shown in Fig No 4.4

2. Secondly, shear walls are provided in the internal frame of the building, similarly $L$ shaped shear walls are provided in the extreme corners of the frame and the middle portion of the structure is provided with lift well, as shown in Fig No 4.5

Table No 1. Different Cases for Analysis

\begin{tabular}{|c|c|c|}
\hline Case No & $\begin{array}{c}\text { Position of Shear Walls in } \\
\text { Building }\end{array}$ & Soil Structure Interaction \\
\hline 1 & $\begin{array}{c}\text { Location of shear wall in } \\
\text { external frame }\end{array}$ & NO \\
\hline 2 & $\begin{array}{c}\text { Location of shear wall in } \\
\text { external frame }\end{array}$ & YES \\
\hline 3 & $\begin{array}{c}\text { Location of shear wall in } \\
\text { internal frame }\end{array}$ & NO \\
\hline 4 & $\begin{array}{c}\text { Location of shear wall in } \\
\text { internal frame }\end{array}$ & NO \\
\hline 5 & No shear wall & \\
\hline
\end{tabular}

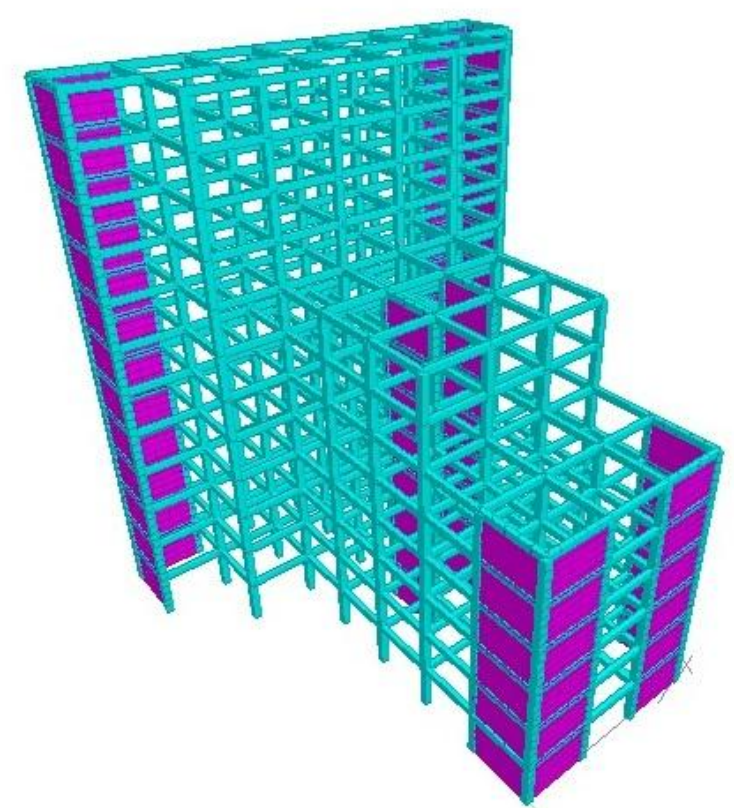

Fig 3.4 isometric view of building having $L$ shaped shear wall in external frame 


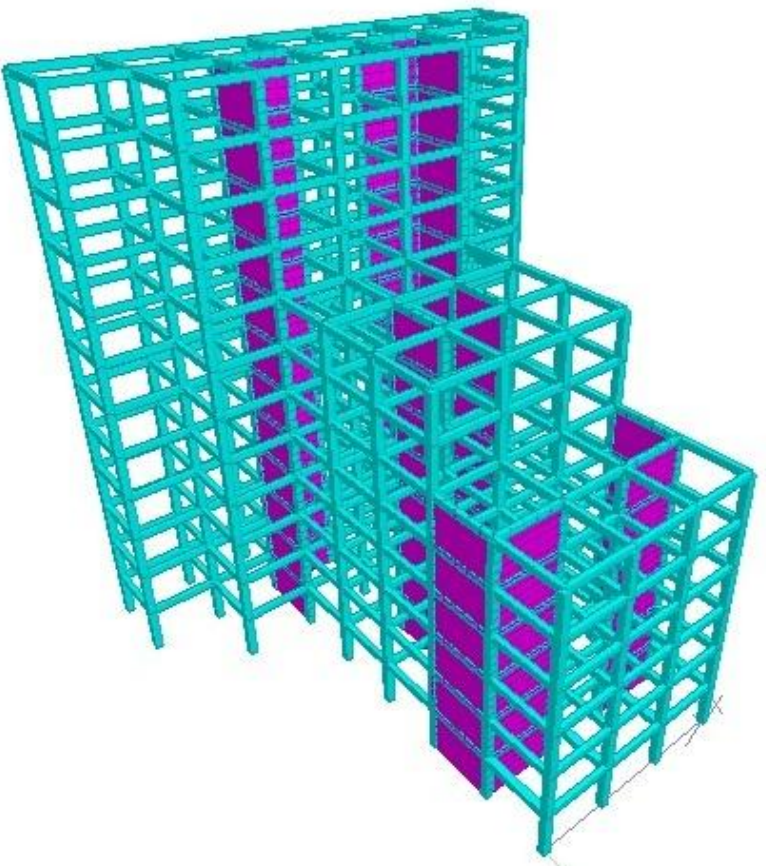

Fig 3.5 isometric view of building having $L$ shaped shear wall in internal frame

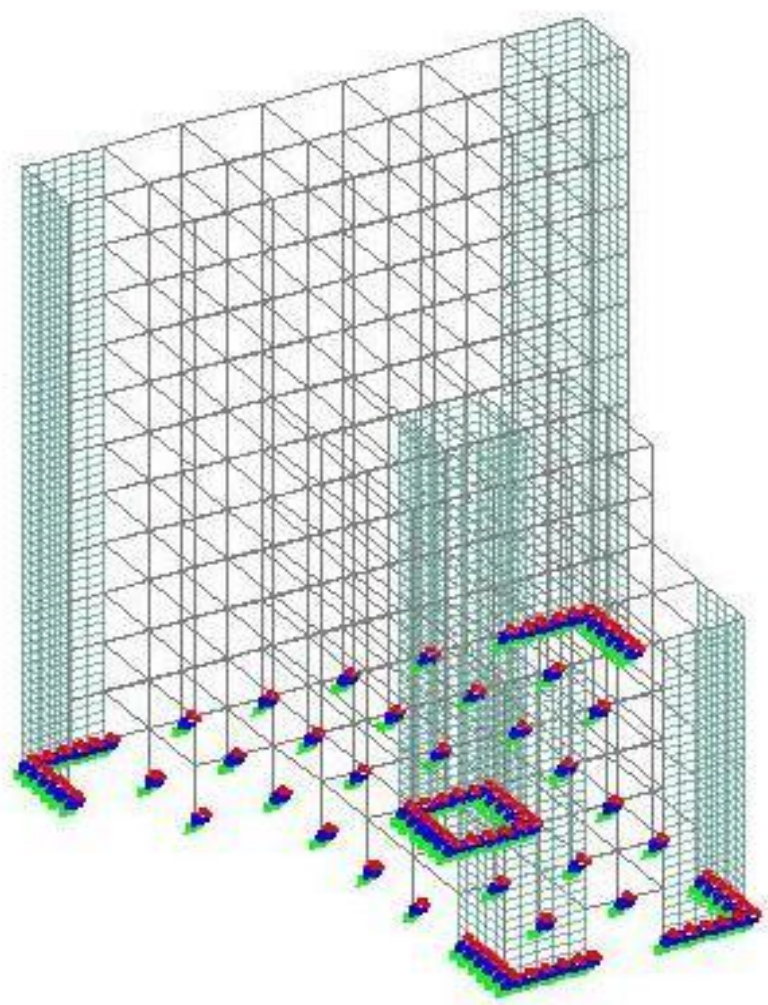

Fig 3.6 isometric view of building having $L$ shaped Shear wall in external frame having spring supports 


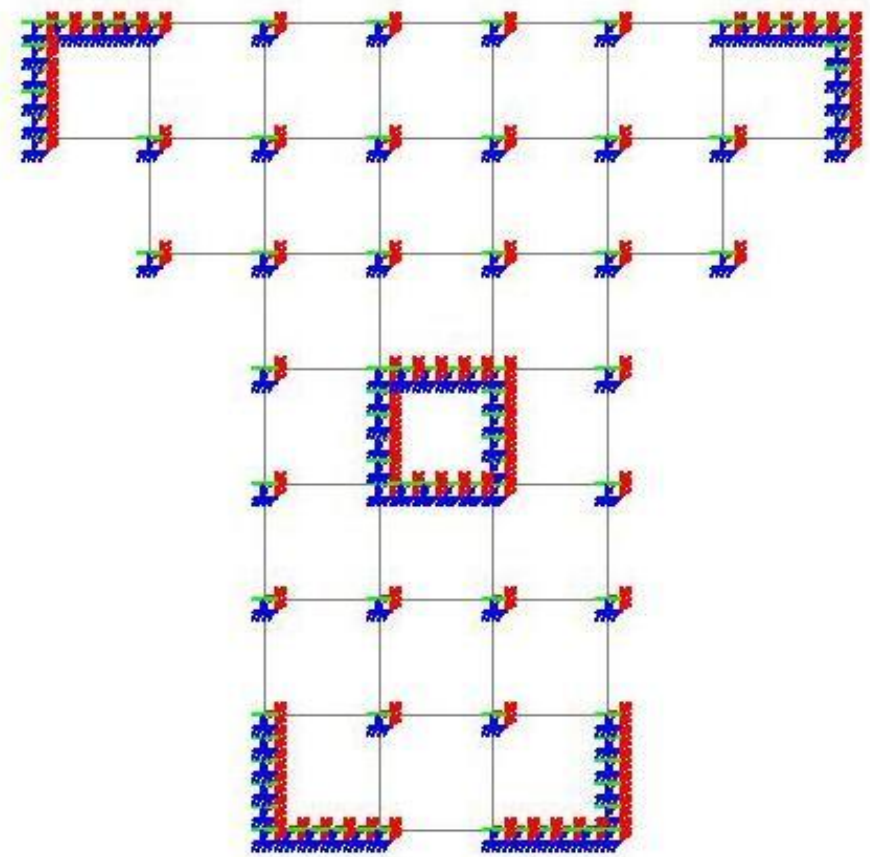

Fig 3.7 Plan of building having $\mathrm{L}$ shaped Shear wall in external frame having spring supports

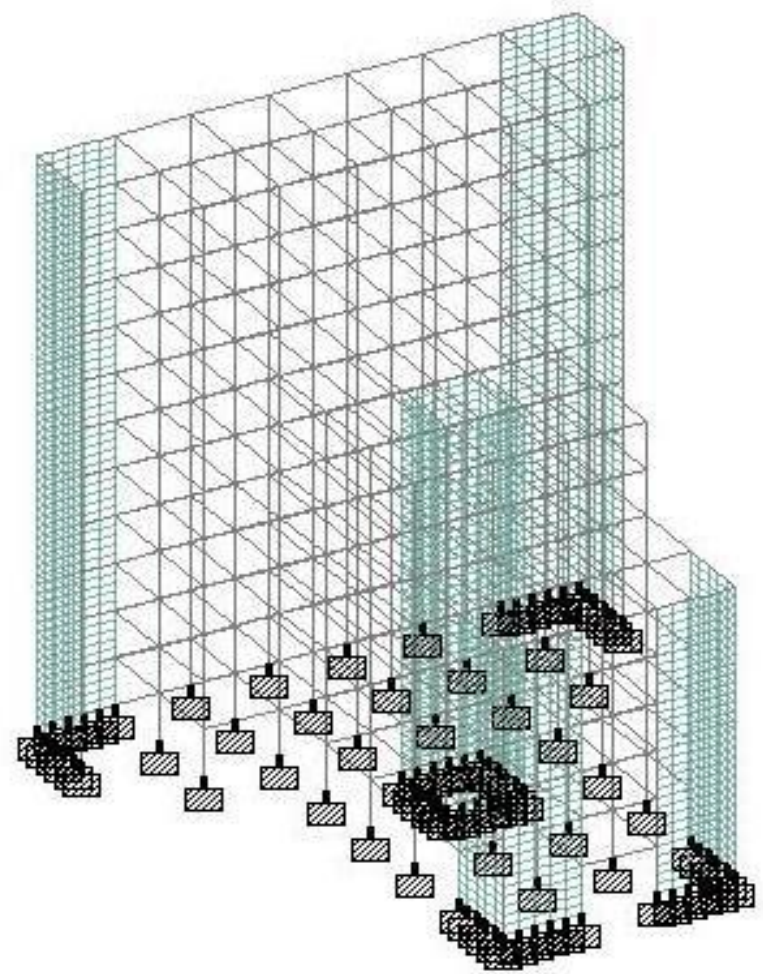

Fig 3.8 isometric view of building having $L$ shaped Shear wall in external frame having fixed supports 


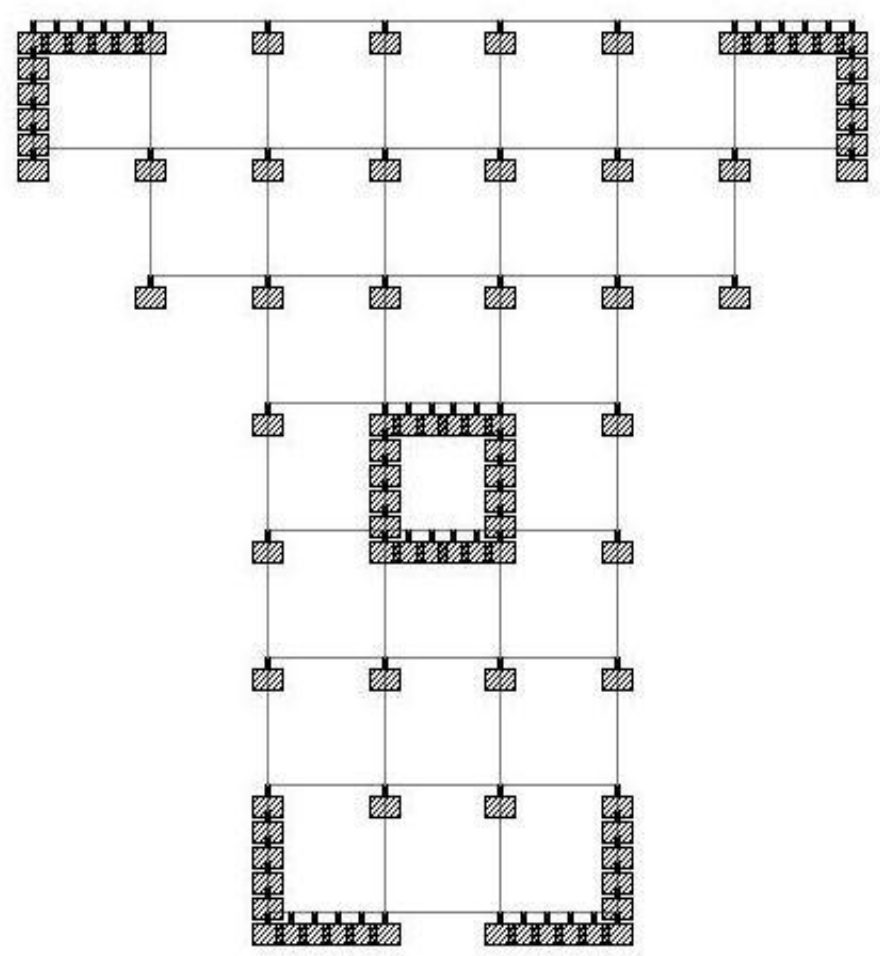

Fig 3.9 Plan of building having $L$ shaped Shear wall in external frame having fixed supports

\subsection{GENERAL}

\section{Analysis}

There are three different methods namely Winkler, Elastic Half Space and Finite element method which can be used for interactive analysis. Among these methods, elastic half space approach have been used in this work. In this chapter apart from description of methods, spring constant values and foundation details have also been given in this chapter.

\subsection{METHODS OF ANALYSIS}

The method used for analysis :-

(i) Elastic Half Space Approach (Richart, Hall and Woods Approach )

\subsection{SPRING CONSTANTS}

Six springs are provided at the base in case of interactive analysis. The stiffness of the springs is evaluated using the relations given in the approach.

\subsubsection{Winkler Approach}

Assumptions:

(i) The super structure, footing and soil mass form a three dimensional integral compatible unit.

(ii) The shear deformations of frame members are neglected.

(iii) All the frame members are prismatic and all the joints act as rigid joints.

(iv) The structure is assumed to behave in a linear elastic fashion.

(v) The soil footing system below an individual structural column could be replaced by a set of six independent elastic springs corresponding to six independent degrees of freedom i.e. three translations and three rotations.

(vi) It has further been assumed that translational spring constant $\mathrm{Kx}=\mathrm{Kz}=\mathrm{Kh}$ and $\mathrm{Ky}=\mathrm{Kv}$.

The rotational spring constants $\mathrm{Krx}=\mathrm{Krz}=\mathrm{K} \Phi$

And Kry $=$ KФ 
Vertical Spring Constant (Kv)

This is defined as a vertical force required to cause unit deflection (in $\mathrm{Y}$ direction) and is expressed in $\mathrm{kN} / \mathrm{m}$. if a cyclic vertical plate load test is carried out on a rigid plate and a plot of pressure, $\mathrm{p}(\mathrm{kN} / \mathrm{m} 2)$ is made versus the elastic settlement $\mathrm{Se}$, then it is found that

Where, Se $=$ Elastic Settlement

$$
\begin{aligned}
& \mathrm{P} \alpha \mathrm{Se} \\
& \mathrm{P}=\mathrm{CuSe}
\end{aligned}
$$

$\mathrm{Cu}=$ coefficient of elastic uniform compression $(\mathrm{kN} / \mathrm{m} 3)$

The value of $\mathrm{Cu}$ for a rigid plate resting on soil is also equal to

And for a flexible plate on soil

$$
\mathrm{Cu}=1.13 \frac{\mathrm{E}}{1-\mu^{2}} \cdot \frac{1}{\sqrt{A}}
$$

$$
\mathrm{Cu}=\frac{C_{s} C}{\sqrt{A}}
$$

Where $\mathrm{C}=\frac{\mathrm{E}}{1-\mu^{2}}$, and

$$
\mathrm{Cs}=\frac{\pi \sqrt{\alpha}}{L \cdot \frac{\sqrt{1+\alpha^{2}}}{\sqrt{1+\alpha^{2}}-\alpha}+\alpha \cdot L \frac{\sqrt{1+\alpha^{2}}+1}{\sqrt{1+\alpha^{2}}-1}-\frac{2}{3}\left[\left(1+\alpha^{2}\right)^{3 / 2}-\frac{1+\alpha^{3}}{\alpha}\right]}
$$

$\alpha=2 \mathrm{a} / 2 \mathrm{~b}$ where ' $\mathrm{a}$ ' and ' $\mathrm{b}$ ' are length and width of foundation respectively

$\mathrm{A}=$ plate area

$\mathrm{E}=$ modulus of elasticity

$\mathrm{L}=$ length of plate or member

$\mu=$ poisson's ratio

In either case $\mathrm{Cu}=\frac{1}{\sqrt{A}}$

Using the subscript ' $p$ ' for the plate, vertical spring constant kvp for the plate could be related to coefficient of elastic compression $\mathrm{Cu}$ as

Where, Ap= area of plate

$$
\mathrm{Kvp}=\mathrm{Cup} A \mathrm{p}
$$

Cup $=$ coefficient of elastic uniform compression for plate (Fig 5.1)

Kvp $=$ vertical spring constant for plate

Ap $=$ area of plate

Using the subscript ' $\mathrm{f}$ ' for the footing, vertical spring constant $\mathrm{Kvf}$ for the actual footing could be related to coefficient of elastic uniform compression $\mathrm{Cu}$ as

$$
\mathrm{Kvf}=\mathrm{Cuf} \text { Af }
$$

Where $\mathrm{Kvf}=$ vertical spring constant for actual foundation

Cuf $=$ coefficient of elastic uniform compression for actual foundation

Now Af $=$ area of actual foundation

$$
\begin{aligned}
& \therefore \quad \frac{K_{v p}}{K_{v f}}= \frac{C_{u p}}{C_{u f}} \cdot \frac{A_{p}}{A_{f}}=\frac{\sqrt{A_{f}}}{\sqrt{A_{p}}} \cdot \frac{A_{p}}{A_{f}}=\left(\frac{A_{p}}{A_{f}}\right)^{0.5} \\
& \text { or } \mathrm{Kvf}=\mathrm{Kvp}\left(\frac{A_{f}}{A_{p}}\right)^{0.5}
\end{aligned}
$$

Therefore the vertical force required to cause unit deflection would be

$$
\mathrm{Kv}=\mathrm{Kvf} \text {. Af }
$$




\subsubsection{Horizontal Spring Constant (Kh):}

This is defined as horizontal force required to cause a unit horizontal deflection. If a cyclic horizontal load test is conducted on a rigid plate and a plot of pressure ( $\tau$ avg $\mathrm{kN} / \mathrm{m} 2$ ) vs elastic horizontal settlement made, the relation is given as

Where $\mathrm{C} \tau=$ coefficient of elastic uniform shear $(\mathrm{kN} / \mathrm{m} 3)$

$$
\tau \operatorname{avg}=\mathrm{C} \tau . \mathrm{Se}
$$

$\mathrm{Se}=$ elastic horizontal displacement in $\mathrm{m}$

Here, $\mathrm{C} \tau=\frac{\mathrm{K}_{\tau} \mathrm{C}}{\sqrt{\mathrm{A}}}$

Where, $\mathrm{C}=\frac{\mathrm{E}}{1-\mu^{2}}$, and

$$
\begin{aligned}
& \mathrm{K} \tau= \frac{\pi}{2 \sqrt{\alpha}\left[\left(\frac{1}{\alpha}\right) \sinh ^{-1}(\alpha)+\sinh ^{-1}\left(\frac{1}{\alpha}\right)-\frac{1}{3}\left\{\left(\frac{1}{\alpha^{2}}\right)\left(\sqrt{1+\alpha^{2}}-1\right)\right\}\right]}+\frac{\pi}{\left(\sqrt{1+\alpha^{2}}-\alpha\right)+\left[\frac{v}{1-v}\right]\left[\left(\frac{1}{\alpha}\right) \sinh ^{-1}(\alpha)\right]} \\
&+\frac{\frac{1}{3}\left[\sqrt{1+\alpha^{2}}-\alpha-\left(2 / \alpha^{2}\right)\left(\sqrt{1+\alpha^{2}}-1\right)\right]}{}
\end{aligned}
$$

$\alpha=a / b$ where ' $a$ ' and ' $b$ ' are the length and width of the footing, respectively.

It is indicated that $\mathrm{C} \tau$ depends on foundation area, decreasing inversely with root of the area, $\mathrm{C} \tau=\frac{1}{\sqrt{\mathrm{A}}}$

Where C $\tau$ p can be obtained from Fig 5.2

$$
\mathrm{Khp}=\mathrm{C} \tau \mathrm{p} A \mathrm{p}
$$

and $\mathrm{Khf}=\mathrm{C} \tau \mathrm{f}$.Af

$$
\begin{gathered}
\frac{K_{h p}}{K_{h f}}=\frac{C_{\tau p}}{C_{\tau f}} \cdot \frac{A_{p}}{A_{f}}=\frac{\sqrt{A_{f}}}{\sqrt{A_{p}}} \cdot \frac{A_{p}}{A_{f}}=\left(\frac{A_{p}}{A_{f}}\right)^{0.5} \\
K_{h f}=K_{h p}\left(\frac{A_{f}}{A_{p}}\right)^{0.5}
\end{gathered}
$$

Therefore the horizontal force required to cause a unit deflection would be

$$
\mathrm{Kh}=\mathrm{Khf} \text {. Af }
$$

\subsubsection{Rotational Spring Constant (KФ)}

As defined earlier, $\mathrm{Krx}=\mathrm{Krz}=\mathrm{K} \Phi$. If a cyclic vertical load is applied on a rigid plate at some eccentricity and the plot made between the moment (vertical load times the eccentricity of the point of application) and the resulting elastic rotation of the plate, this relation is linear.

Viladkar (1983) derived the expression for rotational spring constant and expressed as

$$
K_{\phi}=K_{\phi p}\left(\frac{A_{p}}{A_{f}}\right)^{0.5} \cdot \frac{\left(I_{Z Z}\right)_{f}}{\left(I_{Z Z}\right)_{p}}
$$

Where $K_{\phi}=\frac{2 \pi \alpha \sqrt{\alpha}}{2 \alpha^{2} L\left[\left(\sqrt{4 \alpha^{2}+1}+1\right) /\left(\sqrt{4 \alpha^{2}+1}-1\right)\right]+\sqrt{4 \alpha^{2}+1}-1}$

Rotational spring can also be calculated as

$$
K \phi=\frac{M}{\phi}
$$




$$
\phi=\frac{M\left(1-\mu^{2}\right)}{L^{2} B E} I_{\phi}
$$

$\Phi=$ rotation of the base of the rigid rectangle footing due to moment ' $M$ ' applied in the direction of ' $L$ ' (Fig 5.3).

L \& B are length and width of the footing respectively

$\mathrm{E}=$ Modulus of elasticity of soil

$\mu=$ Poisson's ratio of soil

$\mathrm{I} \Phi=$ influence factor and is function of $\mathrm{L} / \mathrm{B}$ which is given in Table 5.1

Table No 2. Influence Factor

\begin{tabular}{|l|l|l|l|l|l|l|l|l|l|l|}
\hline $\mathrm{L} / \mathrm{B}$ & 0.1 & 0.2 & 0.5 & 1.0 & 1.5 & 2.0 & 5.0 & 10.0 & 100 & $\infty$ \\
\hline $\mathrm{I} \Phi$ & 1.59 & 2.29 & 3.38 & 3.70 & 4.12 & 4.38 & 4.82 & 4.93 & 5.06 & 5.10 \\
\hline
\end{tabular}

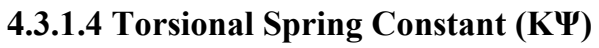

This is defined earlier as kry $=\mathrm{K} \Phi$. If a foundation is acted upon by a moment with respect to vertical axis, it will rotate around this axis. Tests have indicated that angle of rotation $(\Psi)$, of the foundation is proportional to the external moment.

Where

$$
\mathrm{My}=\mathrm{C} \Psi \mathrm{J} \mathrm{y} \Psi
$$

$\mathrm{Jy}=$ polar moment of inertia of the contact area.

$\mathrm{C} \Psi=$ Coefficient of elastic non-uniform shear.

$\mathrm{C} \Psi=1.3 \mathrm{C} \tau$

Torsional spring constant

$$
\begin{array}{r}
\mathrm{K} \Psi=\frac{M_{y}}{\psi}=\mathrm{C} \Psi \mathrm{Jy} \\
=1.3 \mathrm{C} \tau . \mathrm{Jy}
\end{array}
$$

$\mathrm{K \Psi f}=1.3 \mathrm{C} \tau \mathrm{p} \cdot \sqrt{\frac{A_{p}}{A_{f}}} \mathrm{Jyf}$

\subsubsection{Elastic Half Space Approach}

In the Elastic half space approach, the foundation is idealized as the vibrating mechanical oscillator with a circular base resting on the ground. The ground is assumed to be an elastic, homogeneous, isotropic semi infinite body which is referred to as elastic half space.

\subsubsection{Vertical Spring Constant $(\mathrm{Kv})$}

$$
\mathrm{Kv}=\frac{4 \mathrm{Gr}}{(1-\mu)}
$$

Where $\mathrm{G}=$ dynamic shear modulus

$$
\begin{gathered}
\underline{\mu}=\text { Poisson's ratio } \\
\mathrm{r}=\text { Equivalent radius } \\
\mathrm{r}=\sqrt{B L / \pi}
\end{gathered}
$$

Where $\mathrm{L}=$ length of footing

$\mathrm{B}=$ breadth of footing

\subsubsection{Horizontal Spring Constant (Kh)

$$
\mathrm{Kh}=32 \mathrm{Gr}(1-\mu)
$$$$
(7-8 \mu)
$$

Where $\mathrm{G}=$ dynamic shear modulus

$$
\begin{aligned}
& v=\text { Poisson's ratio } \\
& r=\text { Equivalent radius }
\end{aligned}
$$




$$
\mathrm{r}=\sqrt{B L / \pi}
$$

Where $\mathrm{L}=$ length of footing

$\mathrm{B}=$ breadth of footing

\subsubsection{Rocking Spring Constant (KФ)}

$$
\mathrm{K} \Phi=\underline{8 \mathrm{Gr} 3}
$$

$$
\text { Where } \mathrm{r}=\sqrt[4]{\frac{B L^{3}}{3 \pi}}
$$

Where $\mathrm{G}=$ dynamic shear modulus $\mathrm{r}=$ Equivalent radius

Where $\mathrm{L}=$ length of footing

$$
\mathrm{B}=\text { breadth of footing }
$$

\subsubsection{Torsional Spring Constant (K $\Omega)$}

$\mathrm{K} \Phi=\frac{16}{3} \mathrm{Gr} 3$
Where $r=\sqrt[4]{\frac{\mathrm{B} \mathrm{L}\left(\mathrm{B}^{2}+\mathrm{L}^{2}\right)}{6 \pi}}$

Where $\mathrm{G}=$ dynamic shear modulus $\mathrm{r}=$ Equivalent radius

Where $\mathrm{L}=$ length of footing $\mathrm{B}=$ breath of footing

\section{Conclusion}

The structural response of the building frames not only depends upon the properties of the structural elements but also on the position of shear walls and properties of soil on which the structure rests. In the conventional approach the effect of soil is not taken into consideration. In the present work, the analysis of structure has been carried out with and without incorporating the effects of shear wall and soil structure interaction. For the interactive analysis Elastic Half Space approach has been used.

On the basis of analysis of a twelve storey building conventionally designed for rigid foundation condition and then incorporating shear walls and interaction effects using Elastic Half Space approach, the following conclusions may be drawn

I. There is considerable change in the member forces when shear walls and soil interaction is incorporated in the analysis.

II. The axial force in columns decreases when the effect of shear wall is considered in the analysis. The maximum decrease in axial force was observed to be $14.42 \%$ in column C-1. Relatively small change is observed in outer columns other than corner columns with maximum increase up to $11.41 \%$. For the internal column there is decrease in axial force in columns with maximum decrease of $11.64 \%$ using Winkler approach

III. The axial force in exterior column C-1 decreases when shear wall is applied externally and internally, with maximum decrease of $14.73 \%$ and $12.87 \%$ respectively in the analysis and increases when the interaction effect is considered, with maximum increase of $14.34 \%$ externally and $3.73 \%$ internally. The maximum increase in axial force was observed to be $39.41 \%$ in corner columns for Winkler model and $35.21 \%$ for EHS model. Relatively small change Is observed in outer columns other than corner columns with maximum increase upto $11.41 \%$. For the internal column there is decrease in axial force in columns with maximum decrease of $11.64 \%$ using Winkler approach.

IV. Decrease in bending moment is observed for end spans for ad frames both in longitudinal and transverse directions, while in general increase in bending moment is observed for inner spans.

$\mathrm{V}$. For the beams In longitudinal direction the maximum decrease of $65.05 \%$ and maximum increase of $62.12 \%$ was observed in bending moment, in transverse direction maximum increase is of $51.26 \%$ and maximum decrease is of $68.8 \%$ in bending moment. 
VI. More changes are observed in bending moment when Winkler approach is used as compared to EHS approach, reason being non-consideration of shear effect in case of Winkler model.

VII. Large variation in bending moment was observed in exterior frame as compared to interior frame.

VIII. Decrease in shear force is observed for end spans of all the frames and increase is observed for the inner spans. The maximum value of shear force was observed to decrease by $54.11 \%$ by Winkler approach and the maximum increase of $51.0 \%$ was observed using the Winkler approach.

\section{References}

[1]. Meyerhoff, G.G. (1953), "Some recent Foundation Research and its application to design", JI. Structural engineer, London, Vol.31 (Part-1), pp.151-167.

[2]. Lee, I.K (1975), "Structure- Foundation Supporting Soil Interaction Analysis" Proc, Gen. Session of the Sym. On Soil MechanicsRecent Developments, University of New South Wales, Australia, pp. 225-294.

[3]. Mazid, K.I. Cunell, M.D.(1976),"A Theoretical and Experimental Investigation into Soil-Structure Interaction", Geotechnique, London, Vol.26,No.2pp.321-350

[4]. Papadopoulas (1976) ${ }^{4}$ proposed a method for taking into account the rigidity of superstructure. "Seismic response of vertically irregular structures". Vol 119, No.16 Dec 1186

[5]. Jain, O.P., Trihka, D.N. and Jain, S.C. (1975)," Differential Foundation Settlement of High Rise Buildings", Proc.Int. Symp. On Soil-Structure Interaction, vol I.pp.237-244.

[6]. Aurora J.S. et. al, (1993) "Settlement Analysis of Multi-Storey Frame", All India Conference on "Tall Buildings", The Institution of Engineers(I).

[7]. Brown P.T.(1970), "Structure Foundation Interaction Analysis", Proc.Gen. Session of the Symp. on Soil Mechanics-Recent Developments, University of New South Wales, Australia,pp.255-294.

[8]. Adrian M, Chandler, Joseph C. Correnza and Graham L. Hutchinson, "Seismic Torsional Provisions: Influence on Element Energy Dissipation, journal of Structural Engineering ASCE.USA, May 1996.

[9]. Benjamin, J.R and Williams, H.A, "Reinforced Concrete Shear wall Aasamhllts", Jl. Structural Engg., ASCE, Vol. 86, No.ST3,pp $1-32$.

[10]. Chopra, K. Anil \& Goel, R.K., “Evaluation of Torsional Provisios in Seismic Codai”, journal of Structural Engineering ASCE. USA. Vol 117, No.12 Dec 1091.

[11]. Dlnh. V. Thaut and Ichinose. T, "Criterion for preventing formation of storey mechanics In vertically irregular wall buildings", Journal of Advanced Concrete Technology, vol.2 No. 3,oct2004.

[12]. Goel. R.K., "Seismic response of Asymmetric systems-Energy based Approach". Journal of Structural Engineering ASCE, USA, Vol 123, No.11 Nov 1997.

[13]. Gould, P.L., "Interaction of Shear Wall- Frame System in Multistorey Buildings". JI.ACI, Vol.62 No.1,pp 45-70. 